\title{
Estimating SIT-driven population reduction in the Mediterranean fruit fly, Ceratitis capitata, from sterile mating
}

\author{
M. Juan-Blasco ${ }^{1}$, B. Sabater-Muñoz ${ }^{1}$, I. Pla ${ }^{2}$, R. Argilés ${ }^{2}$, \\ P. Castañera ${ }^{3}$, J. A. Jacas ${ }^{4}$, M. V. Ibáñez-Gual ${ }^{5}$ and \\ A. Urbaneja ${ }^{1 *}$ \\ ${ }^{1}$ Instituto Valenciano de Investigaciones Agrarias (IVIA), Centro de \\ Protección Vegetal y Biotecnología, Unidad Asociada de Entomología \\ UJI-IVIA-CIB (CSIC), E-46113 Moncada, Spain: ${ }^{2}$ Departamento de Plagas, \\ Transformaciones Agrarias SA (TRAGSA), E-46980 Paterna, Spain: \\ ${ }^{3}$ Departamento de Biología Medioambiental, Consejo Superior de \\ Investigaciones Científicas (CSIC), Centro de Investigaciones Biológicas \\ (CIB), Unidad Asociada de Entomología IVIA-CIB (CSIC), E-28040 Madrid, \\ Spain: ${ }^{4}$ Departament de Ciències Agràries i del Medi Natural, Universitat \\ Jaume I (UJI), Unitat Associada d'Entomologia UJI-IVIA, Campus del Riu \\ Sec, E-12071 Castelló de la Plana, Spain: ${ }^{5}$ Departament de Matemàtiques, \\ Universitat Jaume I (UJI), Campus del Riu Sec, E-12071 Castelló de la Plana, \\ Spain
}

\begin{abstract}
Area-wide sterile insect technique (SIT) programs assume that offspring reduction of the target population correlates with the mating success of the sterile males released. However, there is a lack of monitoring tools to prove the success of these programs in real-time. Field-cage tests were conducted under the environmental conditions of the Mediterranean coast of Spain to estimate: (a) the mating success of sterile Vienna-8 (V8) Ceratitis capitata males using molecular markers and (b) their efficacy to reduce $C$. capitata populations under six release ratios of wild females to wild males to V8 males (1:0:0, 1:1:0, 1:1:1, 1:1:5, 1:1:10, and 1:1:20). Statistical models were developed to predict: (a) the number of females captured in traps, (b) sperm ID (sterile or not) in spermathecae of the trapped females, and (c) the viable offspring produced, using release ratio and temperature as predictors. The number of females captured was affected by relative humidity. However, its influence in the model was low. Female captures were significantly higher in ratios 1:0:0 compared to ratios where V8 males were released. The proportion of V8 sperm in spermathecae increased with temperature and with the number of $\mathrm{V} 8$ males released, but leveled off between ratios 1:1:10 and 1:1:20. In all seasons, except winter (no offspring), viable offspring increased with temperature and was lowest for ratio 1:1:20. For the first time, a strong negative relationship between proportion of V8 sperm detected by molecular tools and C. capitata offspring was established. The models obtained should contribute to enhance the efficacy of SIT programs against this pest.
\end{abstract}

*Author for correspondence

Phone: + 34963424130

Fax: + 34963424001

E-mail: aurbaneja@ivia.es 
Keywords: fruit flies, mating success, monitoring tool, overflooding ratio, Tephritidae, Vienna-8

(Accepted 21 November 2012; First published online 20 January 2014)

\section{Introduction}

The Mediterranean fruit fly, Ceratitis capitata (Wiedemann) (Diptera: Tephritidae) is a widely distributed pest in the fruitgrowing areas throughout the world (EPPO, 2013) with a wide host range (Liquido et al., 1991; Aluja \& Mangan, 2008). This insect causes direct damage mostly to fruit and therefore it is considered a major economically important pest in fruit production (White \& Elson-Harris, 1992). C. capitata is highly mobile and shows resistance to a wide range of environmental conditions, which facilitates its prevalence and ability to reinvade pest-suppressed areas (Papadopoulos et al., 2001; Meixner et al., 2002; Martínez-Ferrer et al., 2010). In addition, C. capitata is characterized by a mating system based on the complex traits regarding leks, remating, and sperm transfer (Burk \& Calkins, 1983; Hendrichs et al., 2002). Damage caused to fruits and the difficulties in managing this pest are substantial enough to consider the application of large-scale projects focused on reducing or suppressing populations of this insect (Myers et al., 1998; Hendrichs et al., 2007).

The application of tactics designed to interfere with mating as a method to reduce insect populations is a strategy often considered against pest species of economic importance (Liebhold \& Tobin, 2008; Yamanaka \& Liebhold, 2009). The sterile insect technique (SIT) is a species-specific form of birth control for pest populations. It is a powerful tool when applied as a tactic in a system deployed on an area-wide (aw) basis (Klassen, 2005). In Spain, after years of an area-wide control program based on insecticide applications, an aw-integrated pest management program (aw-IPM) has been implemented to reduce the long-term costs of its control. Mass trapping, biological control, selective pesticide applications, chemosterilization, and aw -SIT are used in combination, as part of this aw-IPM (Sabater-Muñoz et al., 2009; Urbaneja et al., 2009; Navarro-Llopis et al., 2011: Tormos et al., 2012; Juan-Blasco et al., 2013a, b). The combination of all these management strategies is aimed at reducing C. capitata populations and consequently the presence of infested fruit and its economic implications.

Successful aw-IPM programs designed against C. capitata in Spain and elsewhere rely on the application of the SIT (Hendrichs et al., 2005). In the context of aw-IPM, the population reduction obtained in economically important pest populations should vastly outweigh the cost of establishing an SIT program, which needs mass-rearing of sterile insects and regular aw releases (Mumford, 2005; Nagel \& Peveling, 2005). Therefore, tools to accurately measure how sterile males interact with the wild populations of $C$. capitata at the field level are needed in order to apply this technique successfully and cost effectively (Vreysen, 2005).

For SIT to be a viable management technique, the success of mating interference must be measured, and this makes the evaluation of SIT efficacy a complex aim to achieve (Katsoyannos et al., 1999; Vreysen, 2005; Yamanaka \& Liebhold, 2009). Currently, SIT programs obtain information about the density of their target wild populations using monitoring trap network systems distributed throughout the release area. The trap network systems are also used to measure the relative abundance of sterile flies, using mark and recapture methods. Finally, program managers use these data to assess the number of sterile males for release (ratios of theoretical wild-type (wt) to sterile male) that will be effective to reduce pest populations (Calkins \& Parker, 2005; Itô \& Yamamura, 2005; Vreysen, 2005). However, the quality of the released sterile males in the field, specifically their sexual competitiveness, is much more important than the overflooding ratio (Barclay, 2005; Itô \& Yamamura, 2005). Owing to their dependence on the reproductive performance of sterile males, ongoing SIT programs should regularly measure the sexual competitiveness of sterile strains competing with wild strains in field-cage trials (FAO/IAEA/USDA, 2003; Calkins \& Parker, 2005). Moreover, environmental variables play a determinant role in other biological traits of fruit flies such as mating behavior, population dynamics, breeding areas, distribution, or movement patterns (Christenson \& Foote, 1960). Therefore, the development of more effective monitoring tools including environmental and behavioral ecology traits such as sexual competitiveness could continue to greatly minimize aw-SIT control failures (Vargas et al., 1983; Hendrichs \& Hendrichs, 1990; Yamagishi et al., 1993; Papadopoulos et al., 2001; Barry et al., 2004; Itô \& Yamamura, 2005).

To date, the impact of the sexual competitiveness of sterile males on offspring has been indirectly measured only by counting the inherent sterility of eggs in fruits and the ratio of $\mathrm{wt}$ to sterile males in traps in the release area (Wong et al., 1986; McInnis et al., 1994; Rendón et al., 2004; Shelly et al., 2007a). Nowadays, the use of molecular techniques is expanding the possibilities to reliably evaluate the role of sterile males in the tephritid species Anastrepha suspensa (Loew) and Bactrocera dorsalis (Hendel) under natural conditions (Fritz et al., 2010; Aketarawong et al., 2011). A polymerase chain reactionrestriction fragment length polymorphism (PCR-RFLP) method has been developed to measure the sexual competitiveness of sterile C. capitata males based on identifying the sperm (wt or sterile Vienna-8 (V8) male) in the spermathecae of fieldtrapped females (San Andrés et al., 2007a; Juan-Blasco et al., 2013a). Models could help us to understand the mating behavior of the sterile males released in the environment and therefore their impact on wild populations. Given that offspring reduction by the SIT is a function of the number of matings between the sterile males and the wild females (McInnis et al., 1994), an additional achievement was accomplished by Juan-Blasco et al. (2013b) who validated the method developed by San Andrés et al. (2007a), which relates the relative increase of mating success of V8 males with a decrease in fruit damage.

The purpose of this study was to investigate the role of environmental factors in affecting the mating activity of sterile C. capitata males after release. This could help to develop new tools to further improve SIT efficacy. The main objective of this research has been to model the population reduction of C. capitata due to the mating success of sterile males, using sterile mating data obtained under field conditions. 


\section{Material and methods}

The study was conducted from June 2010 to June 2011 in Montcada (Valencia, Spain), where C. capitata is a prevalent pest (Urbaneja et al., 2009) and subjected to an aw-SIT program. Ten field-cage tests following the same handling methods, experimental set-up, and evaluation described in Juan-Blasco et al. (2013b) were carried out every $\sim 30$ days under different environmental conditions.

\section{Field-cage site}

The field trial was conducted in an experimental Clementine mandarin [(Citrus clementina Hort. es Y. Tan.) cv. Clemenules] orchard. The site included eighteen 32-yearold Clementine mandarin trees distributed in a row. Each tree was equipped with an anti-thrips screen cage $\left(3 \times 3 \times 3 \mathrm{~m}^{3}\right)$ with a zippered-door ( $1.5 \mathrm{~m}$ high) on one of the sides of the cage. The trees were drip-irrigated and fertilized, weeds were mechanically removed and pesticide treatments were avoided. Trees were pruned to prevent the canopies from touching the walls of the cages or the ground. The physical barrier TangleTrap ${ }^{\circledR}$ (Insect Trap Coating, Contech Enterprises Inc. Victoria, $\mathrm{BC}$, Canada) was sprayed monthly on the trunk to exclude ants (Juan-Blasco et al., 2011) due to the high number of individuals observed on the trees prior to the trial.

\section{Environmental conditions}

Two data logger instruments (Model Testo 175-H2, Testo Ltd., Alton, Hampshire, UK) were randomly placed in the canopy of two trees of the selected row to measure mean temperature and relative humidity ( $\mathrm{RH})$ inside the cages during the test period (Supplementary table 1). Daily minimum and maximum temperatures, hours of daylight (number of hours from sunrise to sunset), cold hours (hours with temperature $<7^{\circ} \mathrm{C}$ ), precipitation and evapotranspiration during the test were obtained from the IVIA Irrigation Technology Service Montcada station (STR-IVIA) (UTMX: 23368.000, UTMY: $4385233.000,58 \mathrm{~m}$ asl) located $150 \mathrm{~m}$ south from the caged trees site (Supplementary table 1).

\section{Insect strains}

The insects used in the trials were obtained from the SIT mass-rearing and emergence facilities located in Caudete de las Fuentes (Valencia, Spain) and Montcada (Valencia, Spain), respectively. The mass-rearing facility of Caudete de las Fuentes is designated to mass-rear the sterile V8 temperature-sensitive lethal $(t s l)$ genetic sexing strain (GSS) mix 2002 strain of $C$. capitata from egg to pupa. During the mass-rearing process, sterile V8 puparia are externally dusted with pink fluorescent dye (Day-Glo ${ }^{\circledR}$ Color Corp., Cleveland, OH, USA). As a consequence, particles of dye are transferred to the ptilinum of the male adults during emergence from pupae. Sterile V8 puparia are irradiated under hypoxia, using an electron accelerator at $105 \pm 10 \mathrm{~Gy}$ dose, to avoid impairing adult longevity (San Andrés et al., 2007b). The SIT emergence facility is used to maintain sterile males from adult emergence from pupae until they reach field release age. In the present study, sterile V8 males were separated after emergence in two types of polypropylene (PP) jars; $4000 \mathrm{ml}$ jars with a ventilated area of $12 \times 11 \mathrm{~cm}^{2}$ holding 250 males and $1000 \mathrm{ml}$ jars with a ventilated area of $9 \times 8 \mathrm{~cm}^{2}$ holding 50 males. V8 males were fed ad libitum only with sugar and water after emergence, the standard pre-release diet in the Spanish SIT program. To simulate actual pre-release conditions at the emergence facility, V8 males were maintained in complete darkness and were subjected to aromatherapy treatment with ginger root oil (GRO) [Zingiber officinale Roscoe (Zingiberaceae)] (Lluch Essence S.L., Prat de Llobregat, Barcelona, Spain) to enhance mating competitiveness (Juan-Blasco et al., 2013c). The SIT emergence facility also hosted a laboratory colony of the wt strain of $C$. capitata, refreshed annually with wild flies collected from field-infested fruits. Newly emerged wt males and females [generations V-IX (year 2010); generations III-VI (year 2011)] were separated by sex into $1000 \mathrm{ml} P$ P jars as before. Jars containing wt flies were maintained at $25 \pm 4^{\circ} \mathrm{C}$, $75 \pm 5 \% \mathrm{RH}$, with natural light in different rooms to prevent any effect due to contact with pheromones from the opposite sex. Wt adult flies were fed ad libitum with water and a mixed diet of sugar and hydrolyzed yeast (Biokar Diagnostics Co., Pantin, France) $(4: 1 ; \mathrm{w}: \mathrm{w})$ to simulate natural food sources (San Andrés et al., 2009).

\section{Field-cage test}

The first day of the test, ten sentinel apples (commercial quality) were individually fitted inside a polyethylene-netting material with a mesh size of $1 \mathrm{~cm}$, and randomly hung within the canopy of each caged tree. Soon after, C. capitata males (wt and sterileV8) were released inside the cages and 15-30 min later, females (wt) were introduced. Five different treatments of $C$. capitata ratios of $\mathrm{wt}$ female to $\mathrm{wt}$ male to sterile V8 male (1:1:0, 1:1:1, 1:1:5, 1:1:10, and 1:1:20) were considered. Treatments consisted of $50 \mathrm{wt}$ females, $50 \mathrm{wt}$ males, and $0,50,250,500$, or 1000 sterile V8 males, respectively. A femalecontrol treatment 1:0:0 (no males) was included. Three replicates per treatment were included in each test. Replicates were randomly distributed among the 18 cages. V8 males were 3 days old, which corresponded with the release age in the Spanish SIT program, to simulate real field conditions (Juan-Blasco et al., 2013c). Wt males and wt females were 7- and 9 days old, respectively, which corresponded to the ages when they are considered to be sexually matured (Shelly et al., 2007b). Twelve hours after release of the females, a Mosquitrap (SanSan Prodesing S.L., Valencia, Spain) baited with BioLure Tripack MedFly Lure ${ }^{\circledR}$ (Suterra Corporate, Bend, OR, USA), with $1 / 6$ of a tablet of Dichlorvos insecticide (Suterra España Biocontrol S.L., Cerdanyola del Vallès, Spain) was hung on each tree. The apples and the trap were removed from trees 2 days after the start of the test.

\section{Capture of wt females in traps}

Females captured in the traps were used to study the mating activity of V8 males following the method developed by San Andrés et al. (2007a). Females were collected from traps and stored in $70 \%$ ethanol at room temperature until their spermathecae were dissected under binocular microscope (Leica MZ6, 6:3:1 zoom range, Leica, Wetzlar, Germany).

\section{Male sperm identification (sperm ID)}

The DNA from each spermathecae was extracted to identify the origin of its sperm content by means of PCR. Two PCRs with the specific markers CcYsp and Ccmt, and a restriction with the HaeIII enzyme were used to determine 
sperm identity (wt or V8) (San Andrés et al., 2007a; Juan-Blasco et al., 2013b). The markers CcYsp and Ccmt detect male sperm (wt or V8) and presence of DNA from C. capitata in the sample, respectively. The digestion with HaeIII of the Ccmt PCR product determines sperm identity in the sample, wt type (sample remains undigested, only a $330 \mathrm{pb}$ band is visualized in agarose gel) or V8 type (sample yields two bands of 190 and $140 \mathrm{pb})$.

\section{$F_{1}$ generation}

The apples exposed to females under the different treatments in the caged trees were individually placed in isolated cups with vermiculite (Europerlita Española S.A., Rubí, Spain) as pupariation substrate. Cups were maintained at $25 \pm 4^{\circ} \mathrm{C}, 75 \pm 5 \% \mathrm{RH}$ with natural light. The number of puparia obtained from each fruit was counted weekly for 1 month.

\section{Statistical analysis}

The numbers of females captured per trap, mated females, females whose spermathecae contained V8 sterile sperm, and $\mathrm{F}_{1}$ puparia per fruit, were counted for each tree. These values were the basis of the model developed to explain the mating efficacy of V8 males in the field. As a first step, these values were expressed as proportions per tree. Treatments were compared with a $\chi^{2}$ test for homogeneity of proportions. To investigate if mating efficacy of V8 males in the field was significantly affected by the treatment and environmental factors, a generalized linear mixed model (GLMM) (Breslow \& Clayton, 1993) was performed for each variable. Treatments (wt female:wt male:sterile V8 male ratio) and environmental factors were included as fixed effects. For the $F_{1}$ puparia, an additional GLMM was obtained considering the proportion of positive V8 sperm detections in spermathecae and environmental factors as fixed effects. The month in which each test was carried out was considered a random effect in all the GLMMs due to the presence of immeasurable effects in the field which could affect the set of data obtained. Selection of the best model was based on the Akaike Information Criterion. Binomial distribution was used to analyze the number of females captured in traps and the detection of sterile V8 sperm in spermathecae. The Poisson distribution was selected to analyze the number of $F_{1}$ puparia per fruit.

Pearson's product-moment correlation was used to study the relationship among the mean data of the environmental factors recorded during days of the tests. The results of these correlations were used to obtain simplest models when possible by including them in only one environmental factor when it resulted correlated with other two or more factors. This method was also used to study the correlation between the females mated per tree and mated females with V8 male sperms per tree.

The predicted values of $F_{1}$ puparia (determined from positive V8 sperm detections and environment data), were used to calculate the percentage of $C$. capitata population reduction in treated trees, using Abbott's formula (Abbott, 1925). The population reduction was used to estimate the impact of released sterile males (treatments 1:1:1, 1:1:5, 1:1:10, and 1:1:20), compared with the control (treatment 1:1:0). In addition, a logarithmic regression was performed to further investigate the relationship between the percentage of
C. capitata population reduction and the proportion of V8 sperm positive detections in the field.

All statistical analyses were performed using Software $\mathrm{R}$ (R Development Core Team, 2013).

\section{Results}

\section{Environmental conditions}

The range of environmental data collected during the tests is shown in Supplementary table 1. Mean temperature was strongly correlated with cold hours $(r=-0.80 ; P<0.0001)$, minimum temperature $(r=0.91 ; P<0.0001)$, maximum temperature $(r=0.84 ; P<0.0001)$, hours of daylight $(r=0.72$; $P<0.0001)$, evapotranspiration $(r=0.88 ; P<0.0001)$, and $\mathrm{RH}$ $(r=-0.59 ; P<0.001)$. Precipitation $(r=-0.05 ; P=0.781)$ was marginally correlated with mean temperature. $\mathrm{RH}$ and precipitation were poorly correlated as well $(r=0.23$; $P=0.206)$.

\section{Capture of wt females in traps}

Throughout the field-cage tests, $709 \mathrm{wt}$ females were captured in traps when they were exposed to the different male ratios (wt:V8). Females were captured under the entire range of observed temperatures from 7 to $27^{\circ} \mathrm{C}$. The maximum number of females captured in a single trap was 36 in the treatment 1:0:0 at a mean temperature of $16^{\circ} \mathrm{C}$. The mean number of captures per tree is shown in Supplementary table 2A. The GLMM analysis revealed that treatment, mean temperature, and RH had a significant effect $(P<0.0001)$ on the number of females captured (number of females captured $=$

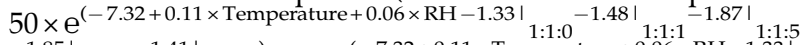

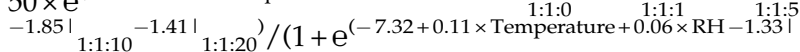
1:1:0 $\left.\left.\left.\left.{ }^{-1:\left.48\right|^{1: 1: 1}}{ }^{-1.87}\right|_{1: 1: 5} ^{1: 20}{ }^{-1.85}\right|_{1: 1: 101: 1: 20}\right)^{\prime}\right)$, whereas precipitation did not $(P>0.05)$. The expected number of captures was higher under the 1:0:0 treatment, compared to treatments 1:1:0, 1:1:1, 1:1:5, 1:1:10, and 1:1:20 $(P<0.0001)$. Under all treatments tested, the probability to capturing wt females in traps gradually increased with temperature (fig. 1).

\section{Sperm ID}

Three hundred and forty-seven females (347) $(=48.9 \%)$ out of the 709 captured, proved positive for molecular sperm detection (Supplementary table 2B). V8 sperm was detected in females $(n=127)$ exposed to treatments in which sterile males were released in ratios of 1:1:1, 1:1:5, 1:1:10, and 1:1:20 (Supplementary table 2C). The detection of V8 sperm in females was strongly correlated with the number of mated females (wt or V8 male) per tree under the treatments 1:1:1 $(r=0.67 ; P<0.0001), 1: 1: 10 \quad(r=0.76 ; P<0.0001)$, and $1: 1: 20$ $(r=0.89 ; P<0.0001)$ (fig. 2). However, this relation was not strong in treatment $1: 1: 5(r=0.31 ; P<0.0001)$. No significant differences were found between treatments $1: 1: 10$ and 1:1:20 in the number of positive V8 sperm detections $\left(\chi^{2}=8.81 ; \mathrm{df}=7\right.$; $P=0.27)$. Analysis of the spermathecae content indicated that V8 matings were determined by treatment $(P<0.0001)$ and mean temperature $(P<0.05)$, and were not influenced by $\mathrm{RH}$ $(P>0.05)$ and precipitation $(P>0.05)$. The probability to detect V8 sperm increased with mean temperature in all treatments where V8 males were released. At a mean temperature of $9^{\circ} \mathrm{C}$ and below, the probability of obtaining positive V8 sperm detections in treatments 1:1:10 and 1:1:20 was below $50 \%$. 


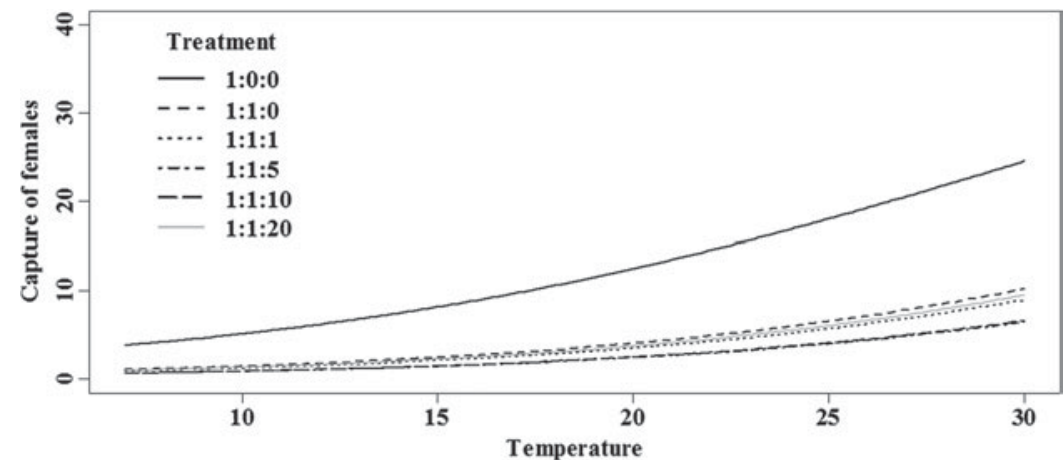

Fig. 1. Probability of capture C. capitata females in traps at different treatments consisting of fly ratios of 1:0:0, 1:1:0, 1:1:5, 1:1:10, and 1:1:20 (wild female:wild male:sterile Vienna-8 males) in relation to temperature and RH. For each treatment the number of released females was 50 individuals, with the corresponding males according the ratios established. The female capture $(y)$ probability is calculated by the formula

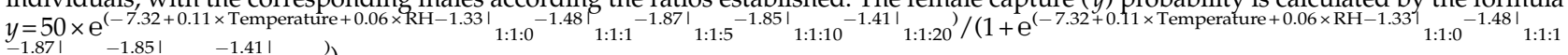

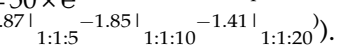
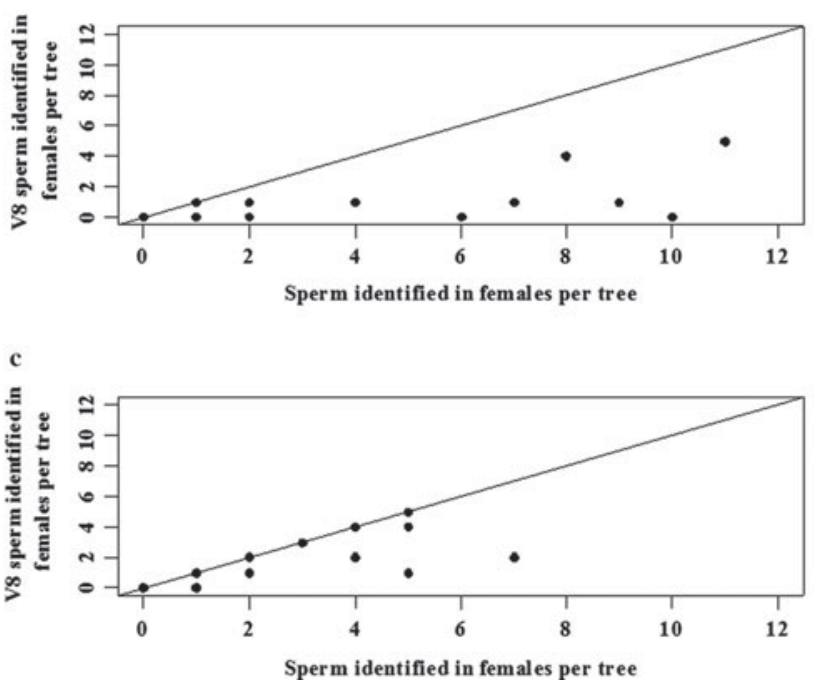

b

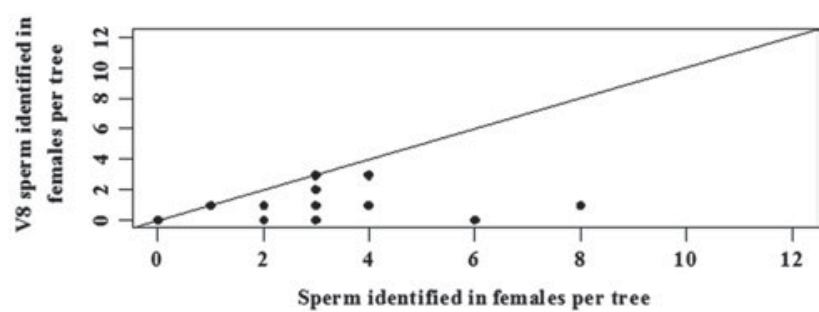

d

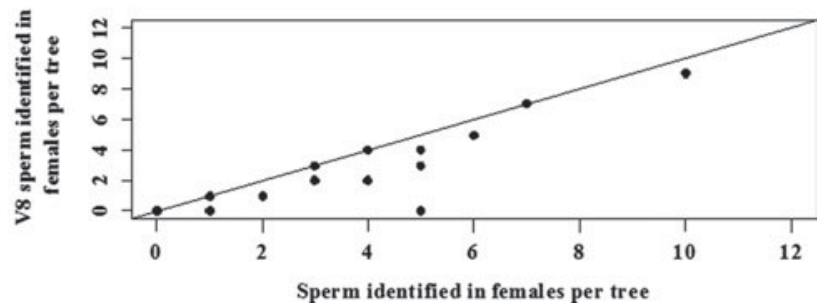

Fig. 2. Relationship between the number of females mated per tree (wt or Vienna-8) and the number of $C$. capitata mated females with Vienna-8 males per tree under treatments (a) 1:1:1, (b) 1:1:5, (c) 1:1:10, and (d) 1:1:20 (wt female:wt male:sterile Vienna-8 male).

On the contrary, V8 sperm detection was above $80 \%$ when mean temperature reached $22^{\circ} \mathrm{C}$ (fig. 3 ).

\section{Puparia from $F_{1}$ generation}

Puparia were only obtained in treatments where females were exposed to males (wt or V8), and this proves that no wild males entered the cages during the assays. No puparia were obtained from fruits exposed to mean temperatures between 7 and $10^{\circ} \mathrm{C}$ (Supplementary table 2D). Treatment and mean temperature had a significant effect on the number of puparia obtained $(P<0.001)$. As expected, the highest number of predicted puparia was obtained in treatment 1:1:0, compared with treatments 1:1:1, 1:1:5, 1:1:10, and 1:1:20 $(P<0.001)$. Furthermore, significant differences from homogeneity were found among ratios where V8 males were released $\left(\chi^{2}\right.$ test, $P<0.0001)$. For all treatments, the number of puparia increased with mean temperature. Under all the temperatures tested, the numbers of predicted puparia in treatments 1:1:10 and 1:1:20 were respectively, 3- and 7-fold lower, compared with treatment 1:1:0. Estimations indicated less than one puparia per fruit at temperatures below $14^{\circ} \mathrm{C}$, irrespective of the male ratio (wt:V8) used. For treatment 1:1:20, the probability of obtaining less than one puparia per fruit was estimated for mean temperatures up to $19^{\circ} \mathrm{C}$ (fig. 4).

\section{Predicting the offspring}

The number of $F_{1} C$. capitata puparia was estimated based on the proportion of V8 positive detections $(P<0.001)$ and the mean temperature $(P<0.001)$ (fig. 5). This relationship, although showed high numbers of V8 matings at higher temperatures, resulted in low puparia reductions. A logarithmic regression was used to show the relationship between V8 sperm detection and population reduction in treated areas, compared with a control area exposed to the same 


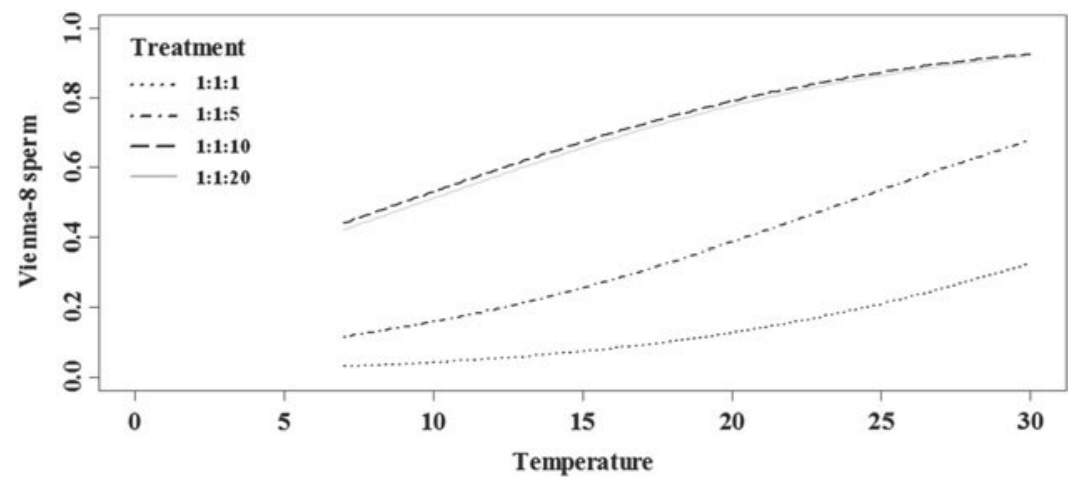

Fig. 3. Proportion of sterile Vienna-8 sperm detections in spermathecae of $C$. capitata females at different fly ratios 1:1:1, 1:1:5, 1:1:10, and 1:1:20 (wild female:wild male:sterile Vienna-8 male) and in relation to temperature. For each treatment the number of released females was 50 individuals, with the corresponding males of each type according to the above indicated ratios. The probability of obtain a proportion of

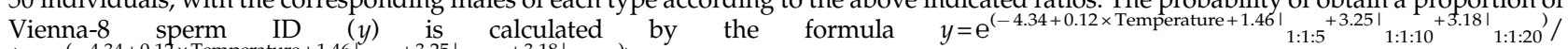

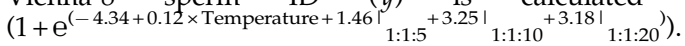

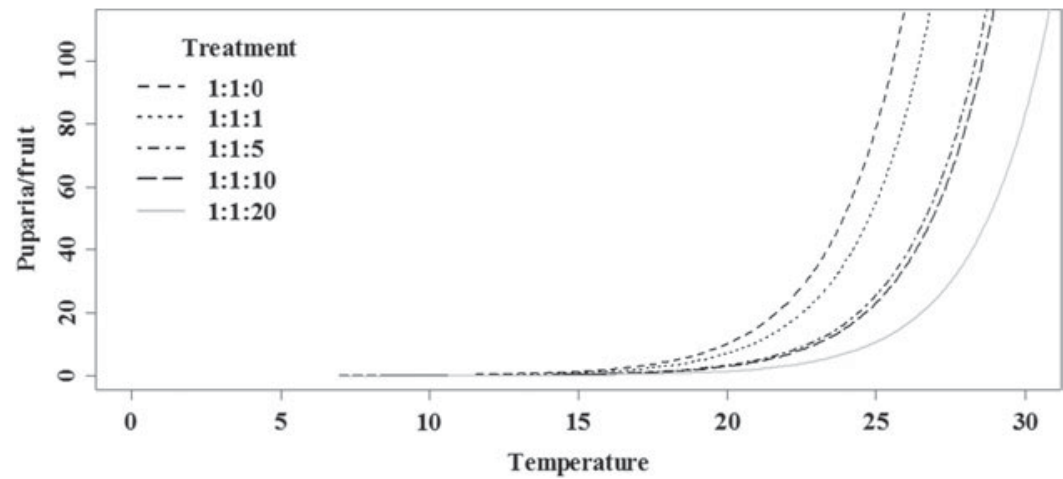

Fig. 4. Number of $C$. capitata puparia obtained from sentinel apple fruits exposed to different fly ratios 1:1:0, 1:1:5, 1:1:10, and 1:1:20 (wild female:wild male:sterile Vienna-8 males) and in relation to temperature. For each treatment the number of released females was 50 individuals, with the corresponding males of each type according the above indicated ratios. The probability of obtain pupae per fruit $(y)$ is calculated by the formula $y=\mathrm{e}^{(-5.87+0.41 \times \text { Temperature }-0.35 \mid} \operatorname{lil}^{-1.13 \mid}{ }_{1: 1: 5^{-1.23 \mid}}^{1: 1: 10^{-1.99 \mid}}$ 1:1:20).

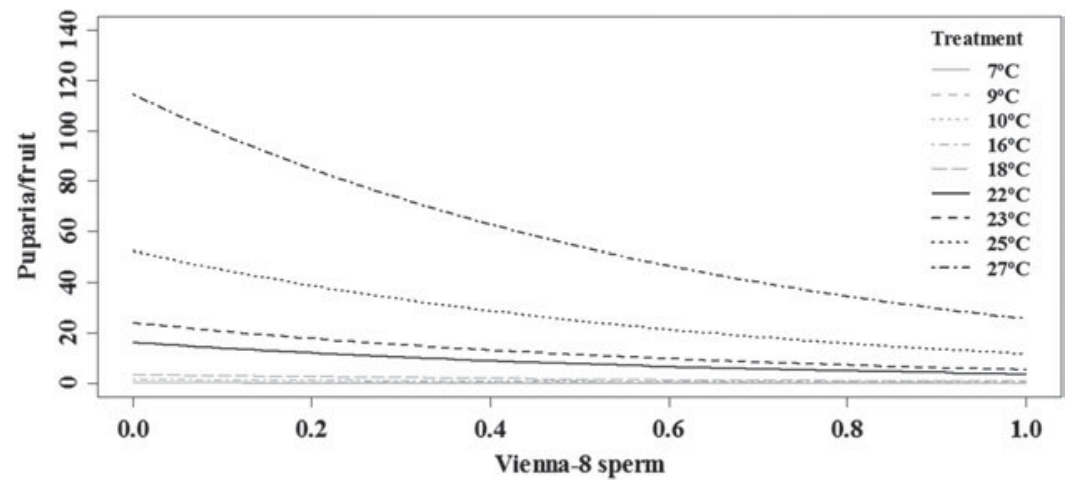

Fig. 5. Probability to obtain C. capitata puparia/fruit at different temperatures and in relation to the proportion of molecular Vienna-8 sperm detected in spermathecae. The number of puparia $(y)$ is determined by temperature and the proportion of molecular Vienna- 8 sperm detected in spermathecae (GLMM Poisson, $P<0.0001)$ and is calculated by the formula $y=e^{(-5.83-(1.50 \times \text { Proportion of positive V8 }}$ detections) $+(0.39 \times$ Temperature) $)$.

environmental conditions (fig. 6). The corrected percentage of C. capitata population reduction was strongly related to the proportion of V8 sperms detected in the captured females.
When V8 sperm detection in females reached 50\%, the predicted population reduction was $52 \%$. The maximum population reduction predicted was $78 \%$, which occurred 


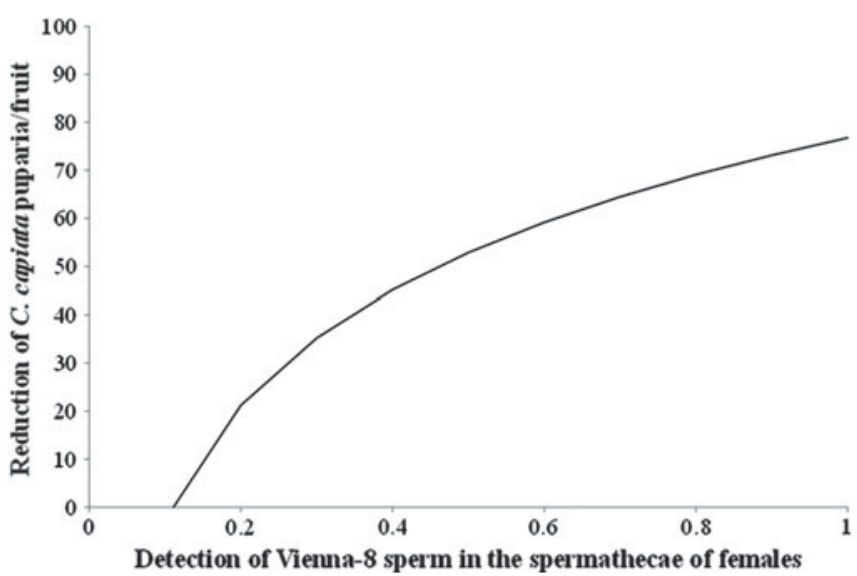

Fig. 6. Reduction of C. capitata puparia (\%) obtained in an SIT area in relation to the variation in the proportion of molecular Vienna-8 sperm ID in spermathecae. $y=34.50 \ln (x)+76.80 ; R^{2}=0.939$.

when V8 sperm was positively detected in $100 \%$ of the females captured.

\section{Discussion}

In agreement with the previous studies, our results demonstrate the influence of environmental factors on the traits that involve reproductive success in insects (Lance \& McInnis, 2005). In the case of SIT releases in the field, both sterile V8 sperm presence in spermathecae and offspring of C. capitata females could be predicted using two variables: (1) ratio of wt females:wt males:V8 males and (2) temperature. Additionally, the number of females captured in traps was also affected by $\mathrm{RH}$. However, the influence of $\mathrm{RH}$ in the final balance of the model was low. Our model was developed for a Mediterranean climate, with low variations in $\mathrm{RH}$ (Supplementary table 2). Therefore, RH may have to be taken into account in SIT programs applied in other climatic areas where $\mathrm{RH}$ variations could play a more important role.

The females captured in traps were a suitable field source of information about the mating success of V8 males. C. capitata female catches are influenced by temperature and $\mathrm{RH}$ in the Mediterranean citrus agroecosystems (Miranda et al., 2001; Navarro-Llopis et al., 2008). Previous studies have showed a decrease in the number of female catches for temperatures $\leq 10^{\circ} \mathrm{C}$, and at low population densities compared to high temperatures when traps contain foodattractants (Miranda et al., 2001; Martínez-Ferrer et al., 2012). It is possible that the male sexual stimulus caused females to be less interested in feeding (Hendrichs \& Hendrichs, 1990) and therefore, they were less attracted to traps that were baited with food attractants. The interpretation of these declines in the number of insects trapped is complex as they may be affected by numerous (often unknown) factors such as age and physiological state (Vreysen, 2005). Trap biases or behavioral response of the insects to traps are two factors that could play a role in female captures (Katsoyannos et al., 1999; Rendón et al., 2004; Vreysen, 2005). It is known that trap density is critical and needs to be adjusted based on factors that include trap and lure/attractant efficiency, climate and geographical location, as well as presence and type of host. Indeed, trapping is a dynamic process that changes according to survey objectives and control applications (IAEA, 2003). Further investigations should therefore explore the efficacy of V8 males using the method proposed on the adjustment of trap density, timing of sampling, and adoption of the molecular method to volume of females trapped at the aw-field scale.

Classic mathematical models have linked the sexual competitiveness of released insects to the wt:sterile ratio obtained from the field traps (Knipling, 1955; Vreysen, 2005). Sterile V8 matings measured using molecular markers showed a higher success rate of male performance with increasing wt:V8 ratios. This result demonstrates that V8 males were as competitive as wt males in sexual and other quality-related parameters such as survival and mating propensity (Holbrook \& Fujimoto, 1970; Barry et al., 2003; Lance \& McInnis, 2005; Vreysen, 2005). V8 males were inferior competitors at temperatures below $9^{\circ} \mathrm{C}$ than at warmer temperatures. The effect of decreasing the temperature at which males are reared in the emergence facility (e.g., from 24 to $15^{\circ} \mathrm{C}$ ) some days before their actual release in the field could improve their competitiveness. The improvement would also imply an increase in the developmental time of their life cycle and therefore of the cost of the program. Further studies are necessary before implementing these changes. The temperature-ratio models obtained (figs 3 and 4) provide useful information to evaluate and therefore, to support the decisionmaking process to improve the efficacy of SIT programs currently underway. The differences between the analysis of field samples and the expected proportion of matings could serve to detect failures of V8 releases in real-time. Similarly, they could be used to detect deviations in the actual wt:V8 male ratios present in the field. Both models, together with the V8 matings-temperature model (fig. 5) highlight the influence of temperature on the mating, oviposition activities, and offspring of C. capitata (Bateman, 1972; Hendrichs \& Hendrichs, 1990; Warburg \& Yuval, 1997; Duyck \& Quilici, 2002). For example, at temperatures below $15^{\circ} \mathrm{C}$, less than one puparia per fruit was predicted even under the 1:1:0 ratio, whereas at temperatures above $19^{\circ} \mathrm{C}$, one or more puparia per fruit was predicted (even at $100 \%$ V8 sperm content in the spermathecae). This result can be taken as indicative of the higher frequency of female remating at high temperatures, a phenomenon that would occur even if wt:V8 male ratio increased. On the other hand, the release of higher numbers of V8 males at low temperatures could be a poor use of 
resources that could be saved to increase the fitness of the sterile males (Pereira et al., 2013). Observations may also assist in improving the management of both low pest densities at the end of winter, and pest outbreaks in summer in Mediterranean climates, which could be satisfactorily managed by implementing other control techniques such as mass trapping (Martínez-Ferrer et al., 2012) or chemosterilization (Navarro-Llopis et al., 2011).

Quantifying the pest offspring reduction in a treated area compared to control area where no sterile males are released constitutes the most powerful straightforward tool to assess the progress in SIT programs (Waterhouse et al., 1976; Vreysen, 2001) since the reproductive potential of the pest in the treated and control areas is determined by the same biological, ecological, and environmental factors (Hendrichs et al., 2002). C. capitata offspring reduction in an SIT-treated area was predicted using the V8 mating success measured directly with molecular markers under Mediterranean climatic conditions (fig. 6). This model helped us to refine the observed over estimations when only ratios and temperature were considered. The maximum offspring reduction estimated was $78 \%$. Therefore, these results confirm the significant influence that traits not specifically considered here can cause increases in the $C$. capitata population under field conditions. These include traits such as remating (Hendrichs \& Hendrichs, 1990; Bonizzoni et al., 2002), mobility, and dispersal, or ability to recolonize areas from alternative hosts (Papadopoulos et al., 2001; Meixner et al., 2002; Martínez-Ferrer et al., 2010). Furthermore, information about the spermathecal content of females not recaptured remains unknown. The possibility to include these parameters to construct the model would qualitatively improve it as a tool to predict the impact of SIT on wild populations.

The molecular method has proved to be a good predictor of C. capitata offspring reduction related with V8 mating success in the field. This method has allowed the development of less laborious and tedious tools to evaluate releases with regards to both efficiency and cost effectiveness in SIT programs. Logically, the essential next step is to validate the models developed using female samples from wild populations. Additionally, this method provides new opportunities for other environmental conditions or fruit fly species under SIT.

\section{Supplementary Material}

The supplementary material for this article can be found at http://www.journals.cambridge.org/BER

\section{Acknowledgements}

M.K. Billah (The University of Ghana) and one anonymous reviewer provided useful comments on early draft of the manuscript. We thank SIT emergence facility (GVA-IVIA) personnel for technical assistance and supply of material, and María Estarlich, Helga Montón and Jose Catalán for technical support in the IVIA laboratory. This work was partially supported by the Ministerio de Ciencia e Innovación, Spain (AGL2010-21349-C02 and AGL2011-30538-C03), IAEA Contract no. 15848, Conselleria d'Agricultura, Pesca i Alimentació de la Generalitat Valenciana and FEOGA. María Juan-Blasco was supported by an IVIA pre-doctoral fellowship and Beatriz Sabater-Muñoz is a recipient of a co-funded Generalitat Valenciana-Instituto Nacional de Investigaciones Agrarias EC-SF fellowship.

\section{References}

Abbott, W.S. (1925) A method of computing the effectiveness of an insecticide. Journal of Economic Entomology 18, 265-267.

Aketarawong, N., Chinvinijkul, S., Orankanok, W., Guglielmino, C.R., Franz, G., Malacrida, A.R. \& Thanaphum, S. (2011) The utility of microsatellite DNA markers for the evaluation of area-wide integrated pest management using SIT for the fruit fly, Bactrocera dorsalis (Hendel), control programs in Thailand. Genetica 139, 129-140.

Aluja, M. \& Mangan, R.L. (2008) Fruit Fly (Diptera: Tephritidae) host status determination: critical conceptual, methodological, and regulatory considerations. Annual Review of Entomology 53, 473-502.

Barclay, H.J. (2005) Mathematical models for the use of sterile insects. pp. 147-174 in Dyck, V.A., Hendrichs, J. \& Robinson, A.S. (Eds) Sterile Insect Technique. Principles and Practice in Area-Wide Integrated Pest Management. Dordrecht, The Netherlands, Springer.

Barry, J.D., McInnis, D.O., Gates, D. \& Morse, J.G. (2003) Effects of irradiation on Mediterranean fruit flies (Diptera: Tephritidae): Emergence, survivorship, lure attraction, and mating competition. Journal of Economic Entomology 96 (3), 615-622.

Barry, J.D., Blessinger, T. \& Morse, J.G. (2004) Recapture of sterile Mediterranean fruit flies (Diptera: Tephritidae) in California's preventative release program. Journal of Economic Entomology 97 (5), 1554-1562.

Bateman, M.A. (1972) The ecology of fruit flies. Annual Review of Entomology 17, 493-518.

Bonizzoni, M., Katsoyannos, B.I., Marguerie, R., Guglielmino, C.R., Gasperi, G., Malacrida, A. \& Chapman, T. (2002) Microsatellite analysis reveals remating by wild Mediterranean fruit fly females, Ceratitis capitata. Molecular Ecology 11, 1915-1921.

Breslow, N.E. \& Clayton, D.G. (1993) Approximate inference in generalized linear mixed models. Journal of the American Statistical Association 88, 9-25.

Burk, T. \& Calkins, C.O. (1983) Medfly mating behavior and control strategies. Florida Entomologist 66 (1), 33-18.

Calkins, C. \& Parker, A. (2005) Sterile insect quality. pp. 269-296 in Dyck, V.A., Hendrichs, J. \& Robinson, A.S. (Eds) Sterile Insect Technique. Principles and Practice in Area-Wide Integrated Pest Management. Dordrecht, The Netherlands, Springer.

Christenson, L.D. \& Foote, R.H. (1960) Biology of fruit flies. Annual Review of Entomology 5, 171-192.

Duyck, P.F. \& Quilici, S. (2002) Survival and development of different life stages of three Ceratitis spp. (Diptera: Tephritidae) reared at five constant temperatures. Bulletin of Entomological Research 92, 461-469.

[EPPO] European and Mediterranean Plant Protection Organization. (2013) PQR - EPPO database on quarantine pests. Available via http://www.eppo.int

[FAO/IAEA/USDA] Food and Agriculture Organization of the United Nations/International Atomic Energy Agency/ United States Department of Agriculture. (2003) Manual for Product Quality Control and Shipping Procedures for Sterile Mass-Reared Tephritid Fruit Flies. pp. 85, Vienna, Austria, International Atomic Energy Agency.

Fritz, A.H., Dhakal, P., Fritz, G.N. \& Kirby, L.A. (2010) Isolating, amplifying and quantifying sperm DNA in Anastrepha suspensa (Diptera: Tephritidae). Florida Entomologist 93 (1), 63-72. 
Hendrichs, J. \& Hendrichs, M.A. (1990) Mediterranean fruit fly (Diptera: Tephritidae) in nature: location and diel pattern of feeding and other activities on fruiting and non-fruiting hosts and nonhosts. Annals of the Entomological Society of America 83 (3), 632-641.

Hendrichs, J., Robinson, A.S., Cayol, J.P. \& Enkerlin, W. (2002) Medfly areawide sterile insect technique programmes for prevention, suppression or eradication: the importance of mating behavior studies. Florida Entomologist 85 (1), 1-13.

Hendrichs, J., Vreysen, M.J.B., Enkerlin, W.R. \& Cayol, J.P. (2005) Strategic options in using sterile insects for area-wide integrated pest management. pp. 563-600 in Dyck, V.A., Hendrichs, J. \& Robinson, A.S. (Eds) Sterile Insect Technique. Principles and Practice in Area-Wide Integrated Pest Management. Dordrecht, The Netherlands, Springer.

Hendrichs, J., Kenmore, P., Robinson, A.S. \& Vreysen, M.J.B. (2007) Areawide integrated pest management (AW-IPM): principles, practice and prospects. pp 3-33 in Vreysen, M.J.B., Robinson, A.S. \& Hendrichs, J. (Eds) Area-Wide Control of Insect Pests: From Research to Field Implementation. Dordrecht, The Netherlands, Springer.

Holbrook, F.R. \& Fujimoto, M.S. (1970) Mating competitiveness of unirradiated and irradiated Mediterranean fruit flies. Journal of Economic Entomology 63 (4), 1175-1176.

[IAEA] International Atomic Energy Agency. (2003) Trapping Guidelines for Area-Wide Fruit Fly Programmes. pp. 48, Vienna, Austria, International Atomic Energy Agency.

Itô, Y. \& Yamamura, K. (2005) Role of population and behavioural ecology in the sterile insect technique. pp. 177-208 in Dyck, V.A., Hendrichs, J. \& Robinson, A.S. (Eds) Sterile Insect Technique. Principles and Practice in Area-Wide Integrated Pest Management. Dordrecht, The Netherlands, Springer.

Juan-Blasco, M., Tena, A., Vanaclocha, P., Cambra, M., Urbaneja, A. \& Monzó, C. (2011) Efficacy of a micro-encapsulated formulation compared with a sticky barrier for excluding ants from citrus canopies. Journal of Applied Entomology 135, 467-472.

Juan-Blasco, M., Urbaneja, A., San Andrés, V., Castañera, P. \& Sabater-Muñoz, B. (2013a) Improving the sterile sperm identification method for its implementation in the areawide Sterile Insect Technique program against Ceratitis capitata (Diptera: Tephritidae) in Spain. Journal of Economic Entomology 106, 2541-2547.

Juan-Blasco, M., Urbaneja, A. \& Sabater-Muñoz, B. (2013a) Improving the sterile sperm identification method for its implementation in the area-wide Sterile Insect Technique program against Ceratitis capitata (Diptera: Tephritidae) in Spain. Journal of Economic Entomology, accepted 10 July 2013. doi:http://dx.doi.org/10.1603/EC13064

Juan-Blasco, M., Sabater-Muñoz, B., Argilés, R., Jacas, J.A., Castañera, P. \& Urbaneja, A. (2013b) Molecular sterile sperm detection to monitor Ceratitis capitata population reduction in SIT programs. Pest Management Science 69, 857-864.

Juan-Blasco, M., San Andrés, V., Martínez-Utrillas, M.A., Argilés, R., Pla, I., Urbaneja, A. \& Sabater-Muñoz, B. (2013c) Alternatives to ginger root oil aromatherapy for improved mating performance of sterile Ceratitis capitata (Diptera: Tephritidae) males. Journal of Applied Entomology 137, 244-251.

Katsoyannos, B.I., Papadopoulos, N.T., Kouloussis, N.A., Heath, R. \& Hendrichs, J. (1999) Method of assessing the fertility of wild Ceratitis capitata (Diptera: Tephritidae) females for use in sterile insect technique programs. Journal of Economic Entomology 92 (3), 590-597.
Klassen, W. (2005) Area-wide integrated pest management and the sterile insect technique. pp. 39-68 in Dyck, V.A., Hendrichs, J. \& Robinson, A.S. (Eds) Sterile Insect Technique. Principles and Practice in Area-Wide Integrated Pest Management. Dordrecht, The Netherlands, Springer.

Knipling, E.F. (1955) Possibilities of insect control or eradication through the use of sexual sterile males. Journal of Economic Entomology 48 (4), 459-462.

Lance, D.R. \& McInnis, D.O. (2005) Biological basis of the sterile insect technique. pp. 69-94 in Dyck, V.A., Hendrichs, J. \& Robinson, A.S. (Eds) Sterile Insect Technique. Principles and Practice in Area-Wide Integrated Pest Management. Dordrecht, The Netherlands, Springer.

Liebhold, A.M. \& Tobin, P.C. (2008) Population ecology of insect invasions and their management. Annual Review of Entomology 53, 387-408.

Liquido, N.J., Shinoda, L.A. \& Cunningham, R.T. (1991) Host plants of the Mediterranean fruit fly (Diptera: Tephritidae): an annotated world review. Miscellaneous Publications of the Entomological Society of America 77, 1-52.

Martínez-Ferrer, M.T., Navarro, C., Campos, J.M., Marzal, C., Fibla, J.M., Bargues, L. \& Garcia-Marí, F. (2010) Seasonal and annual trends in field population of Mediterranean fruit fly, Ceratitis capitata, in Mediterranean citrus groves: comparison of two geographic areas in eastern Spain. Spanish Journal of Agricultural Research 8 (3), 757-765.

Martínez-Ferrer, M.T., Campos, J.M. \& Fibla, J.M. (2012) Field efficacy of Ceratitis capitata (Diptera: Tephritidae) mass trapping technique on clementine groves in Spain. Journal of Applied Entomology 136, 181-190.

McInnis, D.O., Tam, S., Grace, C. \& Miyashita, D. (1994) Population suppression and sterility rates induced by variable sex ratio sterile insect releases of Ceratitis capitata (Diptera:Tephritidae) in Hawaii. Annals of the Entomological Society of America 87, 231-240.

Meixner, M.D., McPheron, B.A., Silva, J.G., Gasparich, G.E. \& Sheppard, W.S. (2002) The Mediterranean fruit fly in California: evidence for multiple introductions and persistent populations based on microsatellite and mitochondrial DNA variability. Molecular Ecology 11, 891-899.

Miranda, M.A., Alonso, R. \& Alemany, A. (2001) Field evaluation of medfly (Dipt., Tephritidae) female attractants in a Mediterranean agrosystem (Balearic Islands, Spain). Journal of Applied Entomology 125, 333-339.

Mumford, J.D. (2005) Application of benefit/cost analysis to insect pest control using the sterile insect technique. pp 481-498 in Dyck, V.A., Hendrichs, J. \& Robinson, A.S. (Eds) Sterile Insect Technique. Principles and Practice in Area-Wide Integrated Pest Management. Dordrecht, The Netherlands, Springer.

Myers, J.H., Savoie, A. \& Van Randen, E. (1998) Eradication and pest management. Annual Review of Entomology 43, 471-491.

Nagel, P. \& Peveling, R. (2005) Environment and the sterile insect technique pp. 499-524 in Dyck, V.A., Hendrichs, J. \& Robinson, A.S. (Eds) Sterile Insect Technique. Principles and Practice in Area-Wide Integrated Pest Management. Dordrecht, The Netherlands, Springer.

Navarro-Llopis, V., Alfaro, F., Domínguez, J., Sanchis, J. \& Primo, J. (2008) Evaluation of traps and lures for masstrapping of Mediterranean fruit fly in citrus groves. Journal of Economic Entomology 101 (1), 126-131.

Navarro-Llopis, V., Vacas, S., Sanchis, J., Primo, J. \& Alfaro, C. (2011) Chemosterilant bait stations coupled with sterile insect technique: an integrated strategy to control the 
Mediterranean fruit fly (Diptera: Tephritidae). Journal Economic Entomology 104 (5), 1647-1655.

Papadopoulos, N.T., Katsoyannos, B.I., Carey, J.R. \& Kouloussis, N.A. (2001) Seasonal and annual occurrence of the Mediterranean fruit fly (Diptera: Tephritidae) in northern Greece. Annals of the Entomological Society of America 94, 41-50.

Pereira, R., Yuval, B., Liedo, P., Teal, P.E.A., Shelly, T.E., McInnis, D.O. \& Hendrichs, J. (2013) Improving sterile male performance in support of programmes integrating the sterile insect technique against fruit flies. Journal of Applied Entomology 137, 178-190.

R Development Core Team (2013) R: A Language and Environment for Statistical Computing. $\mathrm{R}$ Foundation for Statistical Computing, Vienna, Austria. Available via http://www. R-project.org

Rendón, P., McInnis, D.O., Lance, D. \& Stewart, J. (2004) Medfly (Diptera: Tephritidae) genetic sexing: large-scale field comparison of males-only and bisexual sterile fly releases in Guatemala. Journal of Economic Entomology 97 (5), 1547-1553.

Sabater-Muñoz, B., Martins, D.S., Skouri, W., Laurín, C., Tur, C. \& Beitia, F. (2009) Primeros ensayos sobre la utilización de Diachasmimorpha tryoni (Hymenoptera, Braconidae) para el control biológico de Ceratitis capitata (Diptera, Tephritidae) en la Comunidad Valenciana. Levante Agrícola 398, 372-376 (in Spanish).

San Andrés, V., Urbaneja, A., Sabater-Muñoz, B. \& Castañera, P. (2007a) A novel molecular approach to assess mating success of sterile Ceratitis capitata (Diptera: Tephritidae) males in sterile insect technique programs. Journal of Economic Entomology 100 (4), 1444-1449.

San Andrés, V., Ortego, F., Castañera, P. (2007b) Effects of gamma-irradiation on midgut proteolytic activity of the Mediterranean fruit fly, Ceratitis capitata (Diptera: Tephritidae). Archives of Insect Biochemistry and Physiology 65 (1), 11-19.

San Andrés, V., Pérez-Panadés, J., Carbonell, E.A., Castañera, P. \& Urbaneja, A. (2009) Effects of post-teneral nutrition and ginger root oil exposure on longevity and mortality in bait treatments of sterile male Ceratitis capitata. Entomologia Experimentalis et Applicata 132, 256-263.

Shelly, T.E., McInnis, D.O., Rodd, C., Edu, J. \& Pahio, E. (2007a) Sterile insect technique and Mediterranean fruit fly (Diptera: Tephritidae): assessing the utility of aromatherapy in a Hawaiian coffee field. Journal of Economic Entomology 100 (2), 273-282.

Shelly, T.E., Edu, J. \& Pahio, E. (2007b) Age-dependent variation in mating success of sterile male Mediterranean fruit flies (Diptera: Tephritidae): implications for sterile insect technique. Journal of Economic Entomology 100 (4), 1180-1187.
Tormos, J., Asis, J., Sabater-Muñoz, B., Baños, L., Gayubo, S.F. \& Beitia, F. (2012) Superparasitism in laboratory rearing of Spalangia cameroni (Hymenoptera: Pteromalidae), a parasitoid of medfly (Diptera: Tephritidae). Bulletin of Entomological Research 102, 51-61.

Urbaneja, A., Chueca, P., Montón, H., Pascual-Ruiz, S., Dembilio, O., Vanaclocha, P., Abad-Moyano, R., Pina, T. \& Castañera, P. (2009) Chemical alternatives to malathion for controlling Ceratitis capitata (Diptera: Tephritidae), and their side effects on natural enemies in Spanish citrus orchards. Journal of Economic Entomology 102 (1), 144-151.

Vargas, R.I., Harris, E.J. \& Nishida, T. (1983) Distribution and seasonal occurrence of Ceratitis capitata (Wiedemann) (Diptera: Tephritidae) on the island of Kauai in the Hawaiian Islands. Environmental Entomology 12, 303-310.

Vreysen, M.J. (2001) Principles of area-wide integrated tsetse fly control using the sterile insect technique. Medécine Tropicale 61, 397-411.

Vreysen, M. (2005) Monitoring sterile and wild insects in areawide integrated pest management programmes. pp. 325-361 in Dyck, V.A., Hendrichs, J. \& Robinson, A.S. (Eds) Sterile Insect Technique. Principles and Practice in Area-Wide Integrated Pest Management. Dordrecht, The Netherlands, Springer.

Warburg, M.S. \& Yuval, B. (1997) Circadian patterns of feeding and reproductive activities of Mediterranean fruit flies (Diptera: Tephritidae) on various hosts in Israel. Annals of the Entomological Society of America 90, 487-495.

Waterhouse, D.F., LaChance, L.E. \& Whitten, M.J. (1976) Use of autocidal methods. pp. 637-59 in Huffaker, D.B. \& Messenger, P.S. (Eds) Theory and Practice of Biological Control. New York, San Francisco, London, Academic Press.

White, I.M. \& Elson-Harris, M.M. (1992) Fruit Flies of Economic Significance: Their Identification and Bionomics. Wallingford, UK/Canberra, CAB International/Australian Centre for International Agricultural Research.

Wong, T.T.Y., Kobayashi, R.M. \& McInnis, D.O. (1986) Mediterranean fruit fly (Diptera:Tephritidae): methods of assessing the effectiveness of sterile insect releases. Journal of Economic Entomology 79 (6), 1501-1506.

Yamagishi, M., Kakinohana, H., Kuba, H., Kohama, T., Nakamoto, Y., Sokei, Y. \& Kinjo, K. (1993) Eradication of the melon fly from Okinawa, Japan, by means of the sterile insect technique. pp. 49-60 in Proceedings of an IAEA/FAO Symposium «IAEA-SM-327/4-Management of insect pests: $n u-$ clear and related molecular and genetic techniques», 19-23 October 1992, Vienna, Austria.

Yamanaka, T. \& Liebhold, A.M. (2009) Spatially implicit approaches to understanding the manipulation of mating success for insect invasion management. Population Ecology 51, 427-444. 